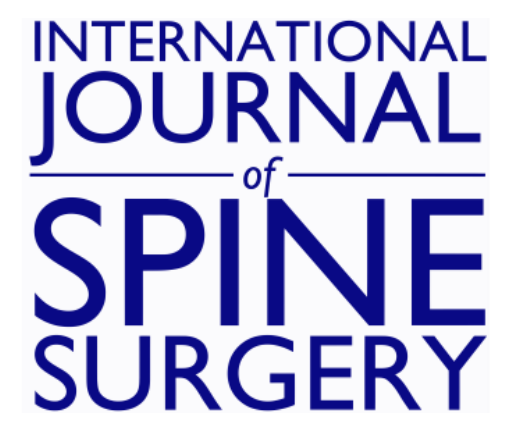

\title{
Regression of Disc-Osteophyte Complexes Following Laminoplasty Versus Laminectomy with Fusion for Cervical Spondylotic Myelopathy
}

Remi M. Ajiboye, Stephen D. Zoller, Adedayo A. Ashana, Akshay Sharma, William Sheppard and Langston T. Holly

Int J Spine Surg 2017, 11 (3)

doi: https://doi.org/10.14444/4017

http://ijssurgery.com/content/11/3/17

This information is current as of April 26, 2023.

Email Alerts Receive free email-alerts when new articles cite this article. Sign up at:

http://ijssurgery.com/alerts

The International Journal of Sphine Surgerby ttp://ijssurgery.com/ by guest on April 26, 2 2397 Waterbury Circle, Suite 1,

Aurora, IL 60504, Phone: +1-630-375-1432

(C) 2017 ISASS. All Rights Reserved. 


\section{Regression of Disc-Osteophyte Complexes Following Laminoplasty Versus Laminectomy with Fusion for Cervical Spondylotic Myelopathy}

Remi M. Ajiboye, MD, ${ }^{1}$ Stephen D. Zoller, MD, ${ }^{1}$ Adedayo A. Ashana, MD, ${ }^{1}$ Akshay Sharma, BA, ${ }^{2}$ William Sheppard, BS, ${ }^{1}$ Langston T. Holly, MD ${ }^{1,3}$ ${ }^{1}$ Department of Orthopaedics, David Geffen UCLA School of Medicine, Los Angeles, USA. ${ }^{2}$ Case Western Reserve School of Medicine, Cleveland, USA. ${ }^{3 D e-}$ partment of Neurosurgery, David Geffen UCLA School of Medicine, Los Angeles, USA.

\section{Abstract}

\section{Background}

Laminectomy with fusion (LF) and laminoplasty are two posterior-based surgical approaches for the surgical treatment of cervical spondylotic myelopathy (CSM). The decompressive effect of these approaches is thought to be primarily related to the dorsal drift of the spinal cord away from ventral compressive structures. A lesser known mechanism of spinal cord decompression following cervical LF is regression of the ventral disc osteophyte complexes which is postulated to result from the alteration of motion across the fused motion segment. The goal of this study was to determine whether regression of the ventral disc-osteophyte complexes occur following laminoplasty and compare the magnitude of this occurrence to cervical laminectomy and fusion.

\section{Methods}

Seventy patients with CSM who underwent pre- and postoperative magnetic resonance imaging (MRI) and were treated with either laminoplasty or LF. The size of the disc-osteophyte complex at all operative levels were measured on pre- and postoperative MRI using digital calipers.

\section{Results}

The laminoplasty group consisted of 25 patients with an average age of 54.9 and a mean of 3.24 surgical levels while the LF group consisted of 45 patients with an average age of 65.4 and a mean of 3.44 surgical levels (age, $\mathrm{p}<$ 0.0001 ; levels, $\mathrm{p}=0.46$ ). The average time interval between pre- and post-operative MRI was 16.2 and 15.6 months in the laminoplasty and LF groups, respectively $(\mathrm{p}=0.91)$. The average time interval between surgery and postoperative MRI was 10.1 and 10.7 months in the laminoplasty and LF groups, respectively $(\mathrm{p}=0.86)$. When comparing pre- and post-operative MRI, there was a $9.59 \%$ decrease in disc-osteophyte complex size from $3.84 \mathrm{~mm} \pm$ 0.74 to $3.47 \mathrm{~mm} \pm 0.86$ in the laminoplasty group compared to a $35.4 \%$ decrease in disc-osteophyte complex size from $4.60 \mathrm{~mm} \pm 1.06$ to $2.98 \mathrm{~mm} \pm 1.33$ in LF group (laminoplasty, $\mathrm{p}<0.0001 ; \mathrm{LF}, \mathrm{p}=0.0067$ ). Using logistic regression analysis, LF, increased time interval between surgery and post-operative MRI, high cobb angle, and straight sagittal alignment were all independently associated with increased disc-osteophyte complex regression ( $p$ $<0.05$ ). No differences in functional outcomes (as defined by mJOA scores) was found between the two surgical techniques.

\section{Conclusions}

In patients with CSM that had a posterior surgical approach, LF is associated with a larger interval regression in disc-osteophyte complex size compared to laminoplasty. This is likely related to the loss of motion of the cervical spine after surgery as governed by Wolff's law and the Heuter-Volkmann's principle. Although the decompressive effect of LF and laminoplasty is primarily related to the dorsal drift of the spinal cord away from ventral compressive structures, disc-osteophyte complex regression likely provides another mechanism of spinal cord decompression. 


\section{Introduction}

Laminectomy with fusion (LF) and laminoplasty are two posterior-based surgical approaches for the surgical treatment of cervical spondylotic myelopathy (CSM). ${ }^{1,2}$ The decompressive effect of these surgical approaches is primarily related to the dorsal drift of the spinal cord away from ventral compressive structures. Although the magnitude of dorsal drift of the spinal cord is thought to be higher in patients with cervical lordosis, laminoplasty and LF are increasingly being used in patients with non-lordotic sagittal alignments. ${ }^{3,4}$ Therefore, dorsal drift of the spinal cord away from ventral compressive structures such as disc-osteophyte complexes may be limited in some of these patients.

In addition to dorsal spinal cord drift, a lesser known mechanism of spinal cord decompression following cervical laminectomy and fusion is regression of the ventral disc osteophyte complex. ${ }^{5}$ This is postulated to result from the alteration of motion across the fused motion segment, and was first described in patients undergoing anterior cervical fusion without resection of the osteophytes. ${ }^{6,7}$ Although laminoplasty is considered to be a motion sparing procedure, loss of cervical motion can occur in many cases following this procedure. As such, regression of disc osteophyte complex may potentially occur in patients undergoing laminoplasty. To date, no comparative studies have directly examined the extent to which decompression of spinal cord occurs through the regression of the disc-osteophyte complexes following laminoplasty versus LF. This is of particular importance in patients with non-lordotic alignments in which the dorsal drift is expected to be less and laminoplasty or LF is being considered. The goal of this study was to determine whether regression of the ventral disc-osteophyte complex occurs following laminoplasty and compare the magnitude of this occurrence to cervical laminectomy and fusion.

\section{Materials and Methods}

The study was reviewed and approved by the institutional review board at our institution. The medical records, preoperative and postoperative radiographs and magnetic resonance imaging (MRI) of the cervi- cal spine were reviewed on all patients undergoing laminoplasty or LF by the senior author (LTH) at more than one consecutive level for CSM between 2006 and 2015. Significant kyphosis and instability were contraindications to laminoplasty while fixed severe kyphosis was a contraindication for LF. Postoperative MRI was routinely obtained in these patients as part of another clinical study.

\section{Inclusion and exclusion criteria}

Inclusion criteria for the study included clinical signs and symptoms of CSM, confirmatory preoperative cervical spine imaging demonstrating a discosteophyte complex of $\geq 3 \mathrm{~mm}$ in antero-posterior diameter. Exclusion criteria for this study included patients with a history of previous cervical spine surgery, concomitant anterior cervical spine surgery, a diagnosis of infection, tumor, central cord syndrome or other acute traumatic event, the simultaneous presence of other diagnosed neurological disorder (such as normal pressure hydrocephalus, Parkinson's disease, polio or multiple sclerosis), postoperative MRIs less than three months from surgery and patients whose MRIs were significantly degraded secondary to metallic artifact or patient movement. Based on the above inclusion and exclusion criteria, 70 patients were enrolled in the study and divided into two groups. The laminoplasty group (A) consisted of 25 patients while the LF group (B) composed of 45 patients.

\section{Surgical management}

All patients in the laminoplasty group had a modified open-door laminoplasty technique with titanium mini-plates with or without allograft bone, as previously described. ${ }^{8}$ Patients in the LF group had a posterior instrumented fusion in addition to decompressive laminectomy. The fusion procedures were performed using bilateral lateral mass screws and rods with local autograft bone.

\section{Radiographic analysis}

Radiographic analysis of preoperative and postoperative MRIs were performed using a single picture archiving and communication system (PACS) viewer and imaging software (Centricity, GE Medical Systems, Milwaukee, WI). Anatomical measurements were performed using digital calipers at uniform 
magnification (200\%). For each analyzed disc level, the exact area of maximum disc-osteophyte complex protrusion was first confirmed on both T2-weighted sagittal and axial images. A digital straight line was then drawn from the midpoint of the posterior aspect of the superior vertebrae to the midpoint of the inferior one on the sagittal cut corresponding to the point of maximal disc-osteophyte complex protrusion. The measurement recorded by digital caliper between the posterior vertebral line and the point of maximal disc-osteophyte complex protrusion was the recorded size of the disc-osteophyte complex size (Figure 1).

Additionally, preoperative cervical alignment was measured by the Cobb angle (C2-7). Lordotic sagittal alignment was defined as Cobb angle $>10$ degrees, straight as 0-10 degrees and kyphotic as $<0$ degrees.

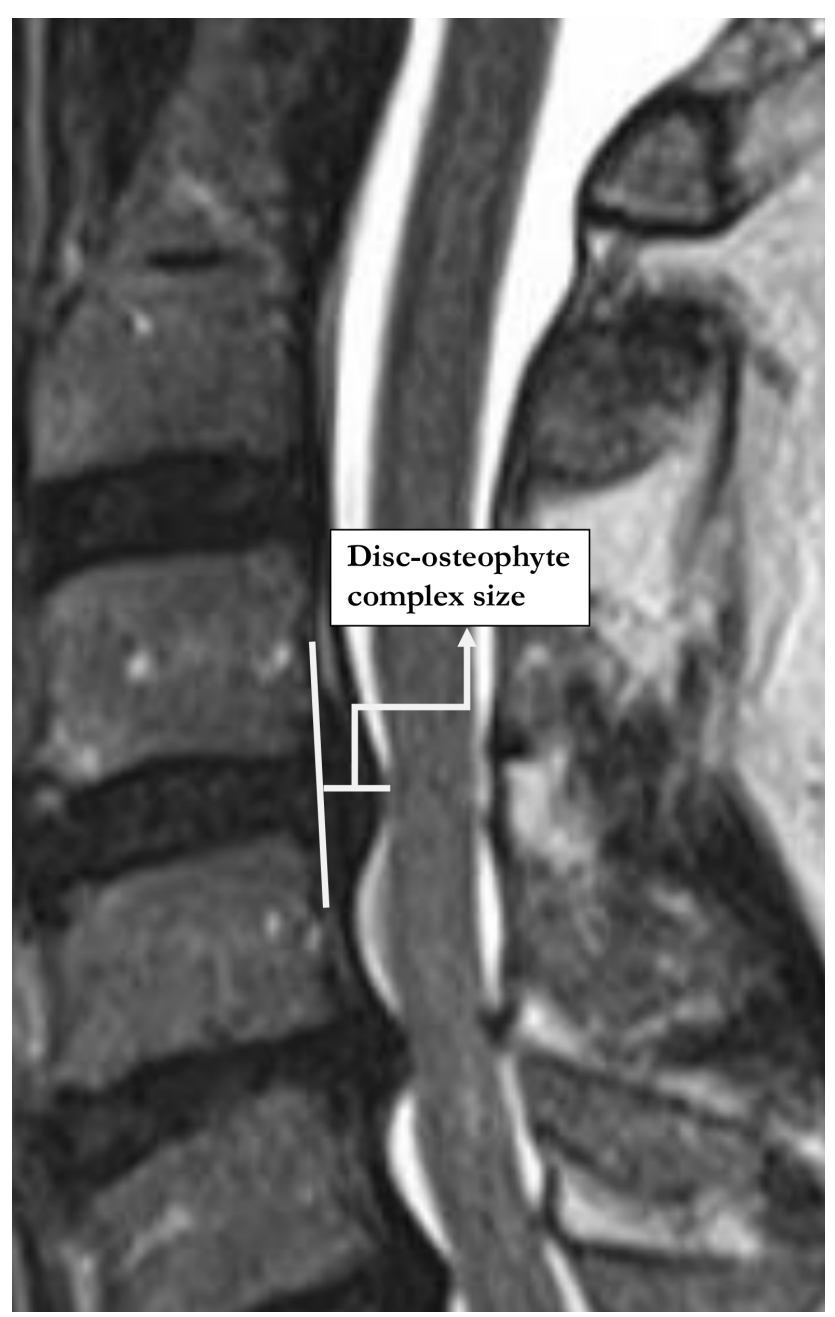

Fig. 1. Illustration of disc-osteophyte complex size measurement.

\section{Functional outcome measure}

The modified Japanese Orthopaedic Association (mJOA) disability scale was calculated preoperatively and postoperatively to quantify each patient's neurological disability.

\section{Statistical analysis}

Patients in the laminoplasty and LF groups were analyzed on the basis of demographic factors (such as age and gender), clinical factors (such as number of levels affected, time between pre- and post-operative MRI, time between surgery and post-operative MRI) and radiographic factors (such as Cobb angle, sagittal alignment, and disc-osteophyte complex size). Differences in continuous variables (such as age, number of levels affected, time between pre- and postoperative MRI, time between surgery and postoperative MRI, and Cobb angle) between both groups were analyzed with unpaired samples t-test. Differences between the pre- and post-operative disc-osteophyte complex size within each group were assessed via two-tailed paired samples t-test. Categorical variables, such as gender and sagittal alignment, were analyzed via Fisher's exact test.

In addition, data were assessed for normality and skewness. Ordinary least squares regression was used to determine the association between discosteophyte complex size reduction and procedural technique, age, gender, number of affected levels, time between pre- and post-operative MRI, time between surgery and postoperative MRI, Cobb angle and sagittal alignment. The variables that were chosen for each model were determined based on availability of the data, as well as on the authors' initial hypotheses about the effects of each variable size reduction. The model was assessed for multicollinearity and homoscedasticity. All analyses with a $p$ value of less than 0.05 were considered statistically significant. The STATA statistical software version 14.0 (STATACorp, College Station, TX) was used to perform the analyses.

\section{Results}

Demographic, clinical and radiographic variables The laminoplasty group (A) consisted of 25 patients, 19 males and 6 females, while the LF group (B) com- 
posed of 45 patients, 30 males and 15 females. Patients in group A were younger than group B (54.9 vs. $65.4, \mathrm{p}<0.0001)$. The mean number of surgical levels was 3.24 in group A compared to 3.44 in group $\mathrm{B}$. The mean Cobb angle was higher in group A compared to group $B$ (10.9 degrees vs. 4.58 degrees, $p=$ 0.0138 ). None of the patients in group $A$ had a kyphotic sagittal alignment compared to group $\mathrm{B}$ which had 15 (33.3\%) patients with kyphosis $(\mathrm{p}=$ 0.0006). There were no differences in time between pre- and post-operative MRI as well as time between surgery and post-operative MRI between each group (Table 1).

\section{Disc-osteophyte complex size and regression}

The mean pre-operative disc-osteophyte complex size in group A was lower than in group B $(3.84 \mathrm{~mm}$ vs. $4.60 \mathrm{~mm}, \mathrm{p}<0.0001)$. Conversely, the mean postoperative disc-osteophyte complex size in group $\mathrm{A}$ was higher than group B $(3.47 \mathrm{~mm}$ vs. $2.98 \mathrm{~mm}, \mathrm{p}=$ $0.0051)$. As such, the difference between pre- and post-operative disc-osteophyte complex size was lower in group A compared to group B ( $0.37 \mathrm{~mm}$ vs. $1.63 \mathrm{~mm}, \mathrm{p}<0.0001)$ (Table 2).

Table 1. Demographic, clinical and radiographic variables.

\begin{tabular}{|c|c|c|c|}
\hline & $\begin{array}{r}\text { Laminoplasty } \\
(\mathrm{n}=\mathbf{2 5})\end{array}$ & $\begin{array}{r}\text { Laminectomy } \\
\text { with Fusion } \\
(\mathrm{n}=45)\end{array}$ & p-value \\
\hline Age, $($ mean \pm SD $)$ & $54.88 \pm 9.05$ & $65.36 \pm 10.08$ & 0.0001 \\
\hline Gender & & & 0.5870 \\
\hline Male $(\%)$ & $19(76 \%)$ & $30(66.6 \%)$ & \\
\hline Female $(\%)$ & $6(24 \%)$ & $15(32.6 \%)$ & \\
\hline Number of levels, $($ mean \pm SD) & $3.24 \pm 1.01$ & $3.44 \pm 1.16$ & 0.4625 \\
\hline $\begin{array}{l}\text { Sagittal alignment (mean in } \\
\text { degrees } \pm \mathrm{SD} \text { ) }\end{array}$ & $10.92 \pm 7.5$ & $4.578 \pm 11.2$ & 0.0138 \\
\hline Lordosis $(\%)$ & $13(52 \%)$ & $14(31.1 \%)$ & 0.1242 \\
\hline Straight (\%) & $12(48 \%)$ & $16(35.6 \%)$ & 0.3228 \\
\hline Kyphosis (\%) & $0(0 \%)$ & $15(33.3 \%)$ & 0.0006 \\
\hline $\begin{array}{l}\text { Time between pre- and } \\
\text { post-operative MRI, (mean in } \\
\text { month } \pm \text { SD) }\end{array}$ & $16.20 \pm 19.07$ & $15.62 \pm 21.29$ & 0.9105 \\
\hline $\begin{array}{l}\text { Time between surgery and } \\
\text { post-operative MRI, (mean in } \\
\text { months } \pm \text { SD) }\end{array}$ & $10.08 \pm 12.87$ & $10.67 \pm 13.4$ & 0.8593 \\
\hline
\end{tabular}

When comparing pre- and post-operative MRI, there was a $9.59 \%$ decrease in disc-osteophyte complex size from $3.84 \mathrm{~mm} \pm 0.74$ to $3.47 \mathrm{~mm} \pm 0.86$ in group A compared to a $35.35 \%$ decrease in disc-osteophyte complex size from $4.60 \mathrm{~mm} \pm 1.06$ to $2.98 \mathrm{~mm} \pm 1.33$ in group B (group A, p < 0.0001; group B, p = 0.0067) (Figure 2, Figure 3, Table 3).

Using logistic regression analysis, surgical treatment of CSM with LF was associated with a discosteophyte complex regression that was on average $1.40 \mathrm{~mm}$ greater than the reduction seen with laminoplasty (95\% CI: $0.78 \mathrm{~mm}-2.03 \mathrm{~mm}, \mathrm{p}<0.001$ ). Increased time interval between surgery and postoperative MRI was associated with disc-osteophyte complex regression, with an average additional $0.04 \mathrm{~mm}$ reduction in disc-osteophyte complex size per month (95\% CI: $0.01 \mathrm{~mm}-0.06 \mathrm{~mm}, \mathrm{p}=0.003$ ). High Cobb angle was also associated with a greater reduction in disc-osteophyte complex size, with an average of $0.07 \mathrm{~mm}$ reduction in disc-osteophyte complex size per degree (95\% CI: $0.01 \mathrm{~mm}-0.14 \mathrm{~mm}$, $\mathrm{p}=0.029$ ). The presence of a straight sagittal alignment was associated with an average disc-osteophyte complex regression size of $1.50 \mathrm{~mm}$ relative to reductions seen with lordotic alignments (95\% CI: $0.46 \mathrm{~mm}$ $-2.54 \mathrm{~mm}, \mathrm{p}=0.006$ ). None of the other analyzed variables (including age, gender, number of affected levels, and time between pre- and post-operative MRI) had statistically significant associations with disc-osteophyte complex regression.

\section{Functional outcome measure}

The mean preoperative mJOA scores in groups $\mathrm{A}$ and $B$ were 13.5 and 13.5 compared to mean postoperative mJOA scores of 15.5 and 15.9 , respectively. Both groups showed an improvement in mJOA

Table 2. Pre- and postoperative disc-osteophyte complex (D-OC) size between groups.

\begin{tabular}{|l|l|l|l|}
\hline & Laminoplasty & $\begin{array}{l}\text { Laminectomy } \\
\text { with Fusion }\end{array}$ & p-value \\
\hline $\begin{array}{l}\text { Preoperative D-OC size (mean } \\
\text { in millimeters } \text { SD) }\end{array}$ & $\begin{array}{l}3.8410 \pm \\
0.7355\end{array}$ & $\begin{array}{l}4.6041 \pm \\
1.0583\end{array}$ & $<0.0001$ \\
\hline $\begin{array}{l}\text { Postoperative D-OC size (mean } \\
\text { in millimeters } \pm \text { SD) }\end{array}$ & $\begin{array}{l}3.4728 \pm \\
0.8553\end{array}$ & $\begin{array}{l}2.9766 \pm \\
1.3330\end{array}$ & 0.0051 \\
\hline $\begin{array}{l}\text { Difference between pre- and } \\
\text { postoperative D-OC size (mean } \\
\text { in millimeters } \pm \text { SD ) }\end{array}$ & $0.3682 \pm$ & $\begin{array}{l}1.6275 \pm \\
1.4450\end{array}$ & $<0.0001$ \\
\hline SD = Standard deviation. & & & \\
\hline
\end{tabular}


scores postoperatively compared to their preoperative values (group A, $+2.0, \mathrm{p}<0.0001$; group $\mathrm{B}$; $+2.35, \mathrm{p}<0.0001)$. However, there was no difference in mJOA score improvement postoperatively between both groups $(\mathrm{p}=0.39)$.

\section{Discussion}

CSM is a challenging disease for both patient and surgeon. Surgical options are multiple, and a recent survey of the Academy of North American Spine Surgeons demonstrated that $70 \%$ of surgeons perform cervical LF for multilevel CSM, while $23 \%$ perform EL and 7\% perform laminectomy alone. ${ }^{9}$ The decompressive effect of laminoplasty and LF occur via dorsal drift of the spinal cord away from ventral compressive structures such as disc-osteophyte com-

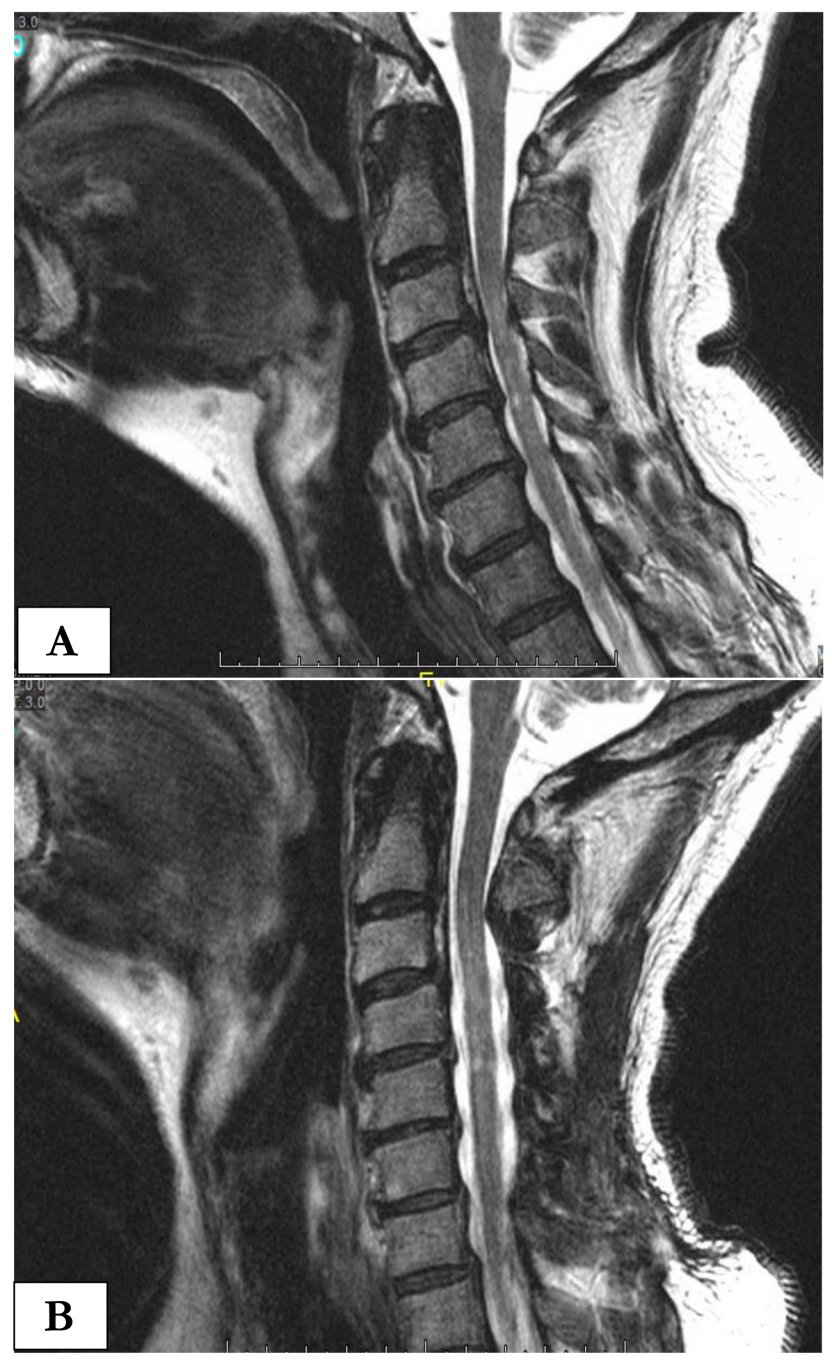

Fig. 2. Preoperative (A) and postoperative (B) sagittal T2 magnetic resonance imaging of a 54 year-old male 6 months following cervical 3-6 laminoplasty. plexes. While the magnitude of dorsal drift of the spinal cord has been shown to be higher in patients with cervical lordosis, laminoplasty and LF are increasingly being used in patients with non-lordotic sagittal alignments. ${ }^{10,11}$ Therefore, dorsal drift of the spinal cord away from disc-osteophyte complexes may be limited in some of these patients. To date, lit-

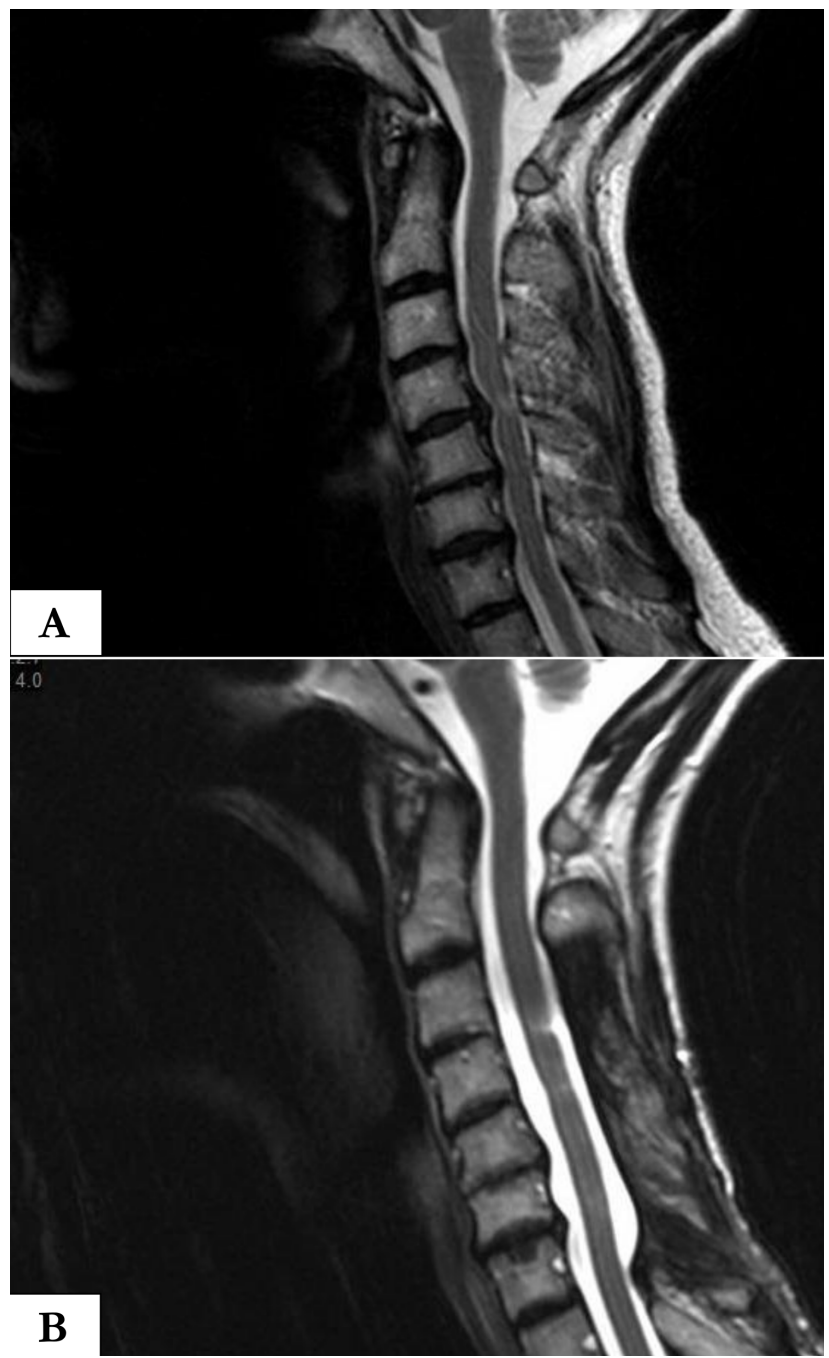

Fig. 3. Preoperative (A) and postoperative (B) sagittal T2 magnetic resonance imaging of a 57-year-old female 6 months following cervical 3-7 laminectomy with fusion. The C4-5 disc osteophyte complex has largely resorbed.

Table 3. Disc-osteophyte complex (D-OC) regression within groups.

\begin{tabular}{|l|l|l|l|} 
& $\begin{array}{l}\text { Difference between pre- } \\
\text { and postoperative D-OC } \\
\text { size (mean in millimeters, } \\
\mathbf{9 5 \%} \mathbf{C I})\end{array}$ & $\begin{array}{l}\text { Percent regression } \\
\text { between pre- and } \\
\text { postoperative } \\
\text { D-OC size }\end{array}$ & p-value \\
\hline Laminoplasty & $0.3682(0.1035-0.6328)$ & $9.59 \%$ & $<0.0001$ \\
\hline $\begin{array}{l}\text { Laminectomy } \\
\text { with Fusion }\end{array}$ & $1.6275(1.3335-1.9214)$ & $35.35 \%$ & 0.0067 \\
\hline $\mathrm{Cl}=$ Confidence interval & & \\
\hline
\end{tabular}


tle is known on the extent to which decompression of spinal cord occurs through the regression of discosteophyte complexes following laminoplasty versus LF. In this study, we demonstrated that in patients with CSM that had a posterior surgical approach, LF is associated with a larger interval regression (35.4\% versus $9.59 \%$ ) in disc-osteophyte complex size compared to laminoplasty. However, no differences in functional outcomes (as defined by mJOA scores) was found between the two surgical techniques.

Symptoms from CSM are due to cervical spinal canal stenosis and subsequent cord compression from redundant ligamentun flavum and disc-osteophyte complexes. ${ }^{12,13}$ It is thought that disc-osteophyte complexes form as a reaction to increased mechanical stress on Sharpey's fibers, which insert into the margins of vertebral bodies adjacent to degenerative intervertebral discs. ${ }^{14}$ These osteophytes arise from the dorsal aspect of adjacent vertebral bodies, ventral to the spinal cord. ${ }^{15}$ Disc-osteophyte complexes may directly cause cord compression, or may function as a tether about which the cord stretches and places tension on dentate ligament attachments; both processes likely contribute to symptoms of CSM..$^{16,17}$

While multiple studies have showed comparable clinical outcomes following laminoplasty or LF for the surgical treatment of CSM, preoperative sagittal alignment of the cervical spine is often used to guide the treatment choice with significant kyphosis and instability often used as a contraindication to laminoplasty while fixed severe kyphosis is used as a contraindication for LF. ${ }^{18-20}$ However, some studies have shown limited effect of sagittal alignment on clinical outcome. A 2015 meta-analysis demonstrated that some loss of lordosis occurs following LF and laminoplasty, with similar clinical outcomes from either procedure. ${ }^{21}$ Another study examined the role of sagittal alignment in precluding laminoplasty, with no correlation between sagittal alignment and outcome. ${ }^{11}$ The reasons for these discordances are unclear. The theory of the current study is that in addition to sagittal alignment, the resorption of ventral disc-osteophyte complexes following posterior-based surgical approach likely provides another mechanism of spinal cord decompression.
While several authors have explored the process of osteophyte resorption following anterior interbody fusion, little is known on resorption following posterior-based decompression..$^{6,714,22}$ Resorption outcomes following anterior fusion are mixed. Early authors demonstrated resorption following anterior fusion, as demonstrated on radiographs. ${ }^{6,7}$ Later, Seo et al. showed in greater than 5 years of follow-up that no evidence of resorption occurred as measured from Computed Tomography scan. They attributed their lack of resorption due to significant apparent cervical spine motion following anterior fusion, as suggested by studies demonstrating residual posterior motion even after successful anterior interbody fusion. ${ }^{23}$ This remaining motion would allow for osteophytes to grow or remain unchanged. ${ }^{22}$

There are several possible explanations for the observed higher regression of disc-osteophyte complexes following LF compared to laminoplasty in this study. Similar to the arguments used by Seo et al., it is likely that motion inversely predicts resorption. ${ }^{22}$ Ashana et al. reported that a significant decrease in the size of disc-osteophyte complexes was observed in patients with CSM treated with LF compared to a control group of patients managed non-operatively in which an increase in disc-osteophyte complexes size was observed. ${ }^{5}$ It is widely accepted that repetitive motion and micro-trauma accelerate degenerative changes in the spine. ${ }^{24-28}$ Multiple studies have shown that a significant proportion of pre-operative range of motion remains following laminoplasty, from $61-81 \%{ }^{29-31}$ Conversely, LF has been shown to allow less range of motion compared to laminoplasty. ${ }^{32}$ With restricted motion following cervical fusion, these degenerative changes may be slowed, stopped, or even reversed, as in the case of disc-osteophyte complex resorption. These findings support the greater resorptive effect of LF compared to laminoplasty due to greater fusion and loss of motion. However, it is still likely that some resorption occurs following laminoplasty due to the small, but demonstrable, loss of motion encountered following this procedure. The principles of Wolff's law and the HeuterVolkmann principles state that bone remodels in response to dynamic stress. ${ }^{33,34}$ A lack of stress on Sharpey's fibers, intervertebral discs, and dentate ligaments following cervical fusion would lead to bone 
resorption via the osteoclast pathway. This concept of less motion equating to more resorption is not new, and is seen in other spinal processes. For example, it is well established that osteophytes are rarely present at sites of congenital or spontaneous fusions in the cervical spine. ${ }^{35}$ In addition, synovial cysts and craniovertebral pannus formation is equated with motion, and the termination of motion is associated with pathology regression, similar to the results observed in our study. ${ }^{36-39}$

Increased time interval between surgery and postoperative MRI, high cobb angle, and straight sagittal alignment were also observed to be associated with increased disc-osteophyte complex regression in this study. Loss of motion following either LF (from maturation of fusion mass) or laminoplasty (from lamina auto-fusion on the hinged-side of the construct) is time dependent and likely explains the findings of increased disc-osteophyte complex regression with prolonged time interval from surgery. Alteration in biomechanical forces on the dorsal aspect of degenerated discs/adjacent vertebral endplate especially with neck motion may explain the effect of sagittal alignment on D-OC regression observed in this study.

\section{Limitation}

There are several limitations to this study. As a retrospective review, it is subject to the common biases and limitations inherent in retrospective analyses. In addition, the decision of laminoplasty versus LF were not randomized and instead were based on sagittal alignment and flexibility of the cervical spine. Additionally, pre-operative neck range of motion was not assessed. Therefore, the role of pre-operative cervical spine functional range of motion on discosteophyte complex regression is unknown. Lastly, the composition of each individual disc-osteophyte complex was not assessed. It is possible that softer disc-osteophyte complexes would more readily reabsorb whereas heavily complexes may be resistant to regression.

\section{Conclusions}

In patients with CSM that had a posterior surgical approach, LF is associated with a larger interval re- gression in disc-osteophyte complex size compared to laminoplasty. However, no differences in functional outcomes (as defined by mJOA scores) was found between the two surgical techniques. Disc-

osteophyte complex regression is likely related to the loss of motion of the cervical spine after surgery as governed by Wolff's law and the Heuter-Volkmann's principle. Although the decompressive effect of LF and laminoplasty is primarily related to the dorsal drift of the spinal cord away from ventral compressive structures, disc-osteophyte complex regression likely provides another mechanism of spinal cord decompression.

\section{References}

1. Matz PG, Anderson PA, Groff MW, et al. Cervical laminoplasty for the treatment of cervical degenerative myelopathy. Journal of neurosurgery. Spine. 2009;11(2):157-169.

2. Anderson PA, Matz PG, Groff MW, et al. Laminectomy and fusion for the treatment of cervical degenerative myelopathy. Journal of neurosurgery. Spine. 2009;11(2):150-156.

3. Aita I, Hayashi K, Wadano Y, Yabuki T. Posterior movement and enlargement of the spinal cord after cervical laminoplasty. The Journal of bone and joint surgery. British volume. 1998;80(1):33-37.

4. Baba H, Uchida K, Maezawa Y, Furusawa N, Azuchi M, Imura S. Lordotic alignment and posterior migration of the spinal cord following en bloc open-door laminoplasty for cervical myelopathy: a magnetic resonance imaging study. Journal of neurology. 1996;243(9):626-632.

5. Ashana AO, Cohen JR, Evans B, Holly LT. Regression of Anterior Disc-osteophyte Complex Following Cervical Laminectomy and Fusion for Cervical Spondylotic Myelopathy. Journal of spinal disorders \& techniques. 2014.

6. Bohlman HH. Cervical Spondylosis with Moderate to Severe Myelopathy: A Report of Seventeen Cases Treated by Anterior Cervical Discectomy and Fusion. Spine. 1977;2:151-162.

7. Robinson RA, Walker AE, Ferlic DC, Wiecking DK. The Results of Anterior Interbody Fusion of the Cervical Spine. J Bone Joint Surg. 1962;44:1569-1587. 
8. Shaffrey CI, Wiggins GC, Piccirilli CB, Young JN, Lovell LR. Modified open-door laminoplasty for treatment of neurological deficits in younger patients with congenital spinal stenosis: analysis of clinical and radiographic data. Journal of neurosurgery. 1999;90(2 Suppl):170-177.

9. Manzano GR, Casella G, Wang MY, Vanni S, Levi AD. A prospective, randomized trial comparing expansile cervical laminoplasty and cervical laminectomy and fusion for multilevel cervical myelopathy. Neurosurgery. 2012;70(2):264-277.

10. Denaro V, Longo UG, Berton A, Salvatore G, Denaro L. Cervical spondylotic myelopathy: the relevance of the spinal cord back shift after posterior multilevel decompression. A systematic review. European spine journal : official publication of the European Spine Society, the European Spinal Deformity Society, and the European Section of the Cervical Spine Research Society. 2015;24 Suppl 7:832-841.

11. Kim SW, Hai DM, Sundaram S, et al. Is cervical lordosis relevant in laminoplasty? The spine journal : official journal of the North American Spine Society. 2013;13(8):914-921.

12. Lebl DR, Bono CM. Update on the Diagnosis and Management of Cervical Spondylotic Myelopathy. The Journal of the American Academy of Orthopaedic Surgeons. 2015;23(11):648-660.

13. Shedid D, Benzel EC. Cervical spondylosis anatomy: pathophysiology and biomechanics. Neurosurgery. 2007;60(1 Supp1 1):S7-13.

14. Stevens JM, Clifton AG, Whitear P. Appearances of posterior osteophytes after sound anterior interbody fusion in the cervical spine: a highdefinition computed myelographic study. Neuroradiology. 1993;35(3):227-228.

15. Radhi Lawrence SUS. Posterior Osteophyte Evolution and its Impact in Cervical Spondylosis: A Literature Review. Journal of Spine. 2013. 16. Kahn EA. The role of the dentate ligaments in spinal cord compression and the syndrome of lateral sclerosis. Journal of neurosurgery. 1947;4(3):191-199. 17. Levine DN. Pathogenesis of cervical spondylotic myelopathy. Journal of neurology, neurosurgery, and psychiatry. 1997;62(4):334-340.

18. Fehlings MG, Wilson JR, Kopjar B, et al. Efficacy and safety of surgical decompression in patients with cervical spondylotic myelopathy: results of the
AOSpine North America prospective multi-center study. The Journal of bone and joint surgery. American volume. 2013;95(18):1651-1658.

19. Furlan JC, Kalsi-Ryan S, Kailaya-Vasan A, Massicotte EM, Fehlings MG. Functional and clinical outcomes following surgical treatment in patients with cervical spondylotic myelopathy: a prospective study of 81 cases. Journal of neurosurgery. Spine. 2011;14(3):348-355.

20. Ghogawala Z, Martin B, Benzel EC, et al. Comparative effectiveness of ventral vs dorsal surgery for cervical spondylotic myelopathy. Neurosurgery. 2011;68(3):622-630; discussion 630-621.

21. Lee CH, Lee J, Kang JD, et al. Laminoplasty versus laminectomy and fusion for multilevel cervical myelopathy: a meta-analysis of clinical and radiological outcomes. Journal of neurosurgery. Spine. 2015;22(6):589-595.

22. Seo JY, Ha KY. Fate of posterior osteophytes in fused segments after anterior cervical discectomy and fusion. Spine. 2012;37(9):741-747.

23. Ha KY, Molon JN, Ahn JH, Kim YH. Fate of osteophytes and sclerosis in fused segments after lumbar fusion. Spine (Phila Pa 1976).

2014;39(18):E1110-1115.

24. Edwards WC, LaRocca H. The developmental segmental sagittal diameter of the cervical spinal canal in patients with cervical spondylosis. Spine (Phila Pa 1976). 1983;8(1):20-27.

25. Morishita Y, Naito M, Wang JC. Cervical spinal canal stenosis: the differences between stenosis at the lower cervical and multiple segment levels. International orthopaedics. 2011;35(10):1517-1522.

26. Wada E, Ebara S, Saito S, Ono K. Experimental spondylosis in the rabbit spine. Overuse could accelerate the spondylosis. Spine (Phila Pa 1976). 1992;17(3 Suppl):S1-6.

27. Kong MH, Morishita $\mathrm{Y}, \mathrm{He} \mathrm{W}$, et al. Lumbar segmental mobility according to the grade of the disc, the facet joint, the muscle, and the ligament pathology by using kinetic magnetic resonance imaging. Spine (Phila Pa 1976). 2009;34(23):2537-2544. 28. Miyazaki M, Hong SW, Yoon SH, et al. Kinematic analysis of the relationship between the grade of disc degeneration and motion unit of the cervical spine. Spine (Phila Pa 1976). 2008;33(2):187-193. 29. Hyun SJ, Riew KD, Rhim SC. Range of motion 
loss after cervical laminoplasty: a prospective study with minimum 5-year follow-up data. The spine journal : official journal of the North American Spine Society. 2013;13(4):384-390.

30. Machino M, Yukawa Y, Hida T, et al. Cervical alignment and range of motion after laminoplasty: radiographical data from more than 500 cases with cervical spondylotic myelopathy and a review of the literature. Spine (Phila Pa 1976).

2012;37(20):E1243-1250.

31. Suk KS, Kim KT, Lee JH, Lee SH, Lim YJ, Kim JS. Sagittal alignment of the cervical spine after the laminoplasty. Spine (Phila Pa 1976).

2007;32(23):E656-660.

32. Heller JG, Edwards CC, 2nd, Murakami H, Rodts GE. Laminoplasty versus laminectomy and fusion for multilevel cervical myelopathy: an independent matched cohort analysis. Spine (Phila Pa 1976). 2001;26(12):1330-1336.

33. Frost HM. Mechanical determinants of bone modeling. Metabolic bone disease \& related research. 1982;4(4):217-229.

34. Frost HM. An approach to estimating bone and joint loads and muscle strength in living subjects and skeletal remains. American journal of human biology: the official journal of the Human Biology Council. 1999;11(4):437-455.

35. Friedenberg ZB, Edeiken J, Spencer HN, Tolentino SC. Degenerative changes in the cervical spine. The Journal of bone and joint surgery. American volume. 1959;41-a(1):61-70 passim.

36. Ito $\mathrm{T}$, Hayashi M, Ogino T. Retrodental synovial cyst which disappeared after posterior C1-C2 fusion: A case report. Journal of orthopaedic surgery (Hong Kong). 2000;8(1):83-87.

37. Lagares A, Arrese I, Pascual B, Gomez PA, Ramos A, Lobato RD. Pannus resolution after occipitocervical fusion in a non-rheumatoid atlanto-axial instability. European spine journal : official publication of the European Spine Society, the European Spinal Deformity Society, and the European Section of the Cervical Spine Research Society. 2006;15(3):366-369.

38. Parks RM, Konig MA, Boszczyk B, Shafafy M. Transarticular fusion for treatment of cystic lesion arising from an odontoid fracture. European spine journal : official publication of the European Spine Society, the European Spinal Deformity Society, and the European Section of the Cervical Spine Research Society. 2013;22(1):21-25.

39. Zygmunt $S$, Saveland H, Brattstrom H, Ljunggren B, Larsson EM, Wollheim F. Reduction of rheumatoid periodontoid pannus following posterior occipito-cervical fusion visualised by magnetic resonance imaging. British journal of neurosurgery. 1988;2(3):315-320.

\section{Disclosures \& COI}

Dr. Holly consults for and receives royalties from Medtronic. The other authors declare no relevant disclosures. This study was funded by a research grant from the National Institutes of Health.

\section{Corresponding Author}

Langston T. Holly, M.D., Professor of Neurosurgery and Orthopaedics, Vice Chair, Clinical Affairs Department of Neurosurgery, David Geffen UCLA School of Medicine, 300 Stein Plaza, Ste. 562, Los Angeles, CA 90095. 1holly@mednet.ucla.edu.

Published 12 June 2017.

This manuscript is generously published free of charge by ISASS, the International Society for the Advancement of Spine Surgery. Copyright @ 2017 ISASS. To see more or order reprints or permissions, see http://ijssurgery.com. 